\title{
Language Description, Documentation and Revitalisation of Languages in Malaysia
}

\author{
Peter K. Austin \\ pa2@soas.ac.uk \\ SOAS, University of London \\ Stefanie Pillai \\ stefanie@um.edu.my \\ Universiti Malaya
}

\section{Introduction}

There are an estimated 137 languages currently spoken in Malaysia ${ }^{1}$, including:

- languages that are indigenous to East Malaysia (Sabah and Sarawak) such as Iban, Kadazan and Bidayuh;

- languages that are indigenous to Peninsular Malaysia such as Semai, Temiar and Jakun;

- Standard Malay (Bahasa Malaysia) and its various geographical and social varieties such as Kelantan Malay, Kedah Malay and Perak Malay;

- other South-East Asian languages, such as Javanese, Minangkabau and Bugis;

- Sinitic (Chinese) languages such as Mandarin, Cantonese, Hokkien and Hakka;

- languages originating from South Asia, including Dravidian languages such as Tamil, Telugu and Malayalam, as well as Indo-Aryan languages like Punjabi and Gujarati;

- creole languages, including Baba Malay, Chitty Malay, and Malacca Portuguese;

- Malaysian Sign Language (Bahasa Isyarat Malaysia); and

- Malaysian English and its sociolinguistic variants, such as Colloquial Malaysian English.

The national and official language in Malaysia is Bahasa Malaysia, which is the main medium of instruction in public education. Bahasa Isyarat Malaysia (BIM) was officially recognised for

\footnotetext{
${ }^{1}$ https://en.wikipedia.org/wiki/Languages_of_Malaysia (accessed 2020-06-29)
} 
communication with and among the deaf community ${ }^{2}$, but Kod Tangan Bahasa Malaysia (KTBM), a manually coded form of Malay, is used to teach deaf students in schools (Bell, Ibrahim, Ho \& Lim, 2015).

Primary education is also available through the medium of Mandarin Chinese and Tamil (Asmah Haji Omar, 2016), and the increasing number of international schools in the country has led to more Malaysians being educated in English. In terms of languages offered as a subject, only three indigenous languages are taught in schools at present (Alias Abd Ghani, 2015; Smith, 2003), namely Iban (in Sarawak), Kadazandusun (in Sabah), and Semai (in Peninsula Malaysia).

A majority of the languages in Malaysia, other than Malay and English, are considered as being threatened as they tend to be spoken by older generations and are not being passed on to children (see Coluzzi, 2017). This is particularly the case with indigenous languages and Chinese varieties other than Mandarin. As the number of fluent speakers and contexts of use dwindle, the need to document and describe these languages and their situations of use becomes more urgent and necessary for language maintenance and revitalisation efforts. In this thematic issue on the description, documentation and revitalisation of languages in Malaysia, we offer six studies related to threatened languages in Malaysia. We begin with three articles centred around particular indigenous languages in Sarawak. The fourth article is a case study of a Chinese language spoken in Sabah, which is under pressure from Mandarin, Malay and English. The fifth article shows the diversity of heritage languages spoken by a group of Malaysian undergraduate students, and the changing intergenerational patterns of language use within their families. The final article deals with Malaccan Portuguese and its linguistic history.

This issue begins with Charlotte Hemmings' article that provides a comprehensive description of the research methods she employed in a documentation project on Kelabit, an indigenous language spoken in Northern Sarawak. Hemmings describes the entire set of processes involved in her project from the recording instruments used, how she names files and collects metadata, her data collection methods, and the transcription and translation conventions she employs. She goes on to discuss and assess the various methods and approaches used in the project, thus providing an account of good practices for other language documenters and researchers to observe.

\footnotetext{
${ }^{2}$ Persons with Disabilities Act 2008
} 
The second article by Peter Sercombe examines the notion of identity among another indigenous group in Sarawak, the East Penans. The focus of this article is how identity and its expression through language is changing in relation to changes in the Penan's socio-economic context, as they move from being primarily nomadic hunter-gatherers to a more sedentary lifestyle. Sercombe begins his article by discussing the concept of identity and hunter-gatherers, before describing the East Penans and their language. Sercombe outlines the socio-cultural characteristics related to an Eastern Penan identity (e.g., language, cultural practices connected to food, appearance and accessories worn) to assesses the extent to which the community has assimilated to other neighbouring indigenous groups.

This next article also focuses on Sarawak, but from the context of development and revitalisation initiatives for the indigenous language Bidayuh. Here, Patricia Riget and Yvonne Campbell focus on two language and culture support initiatives: the Bidayuh Language Development Preservation (BLDP) Project and the Multilingual Education (MLE) Project. Riget and Campbell discuss the extent to which the participants in their study feel that these projects were successful. They conclude with suggestions to improve revitalisation initiatives for Bidayuh.

East Malaysia continues as a focus with the next article by Chih-I Liao, which is a case study of family language polices in four Hakka families in Sandakan, Sabah. Her study suggests that even if families want to maintain their heritage language and culture, external pressure may lead them to choose to speak Mandarin rather that Hakka at home. Over time, community-wide decisions of this type lead to language shift and loss.

The geographic focus moves to West Malaysia with the next two articles. Paolo Coluzzi discusses the diversity of heritage languages among a group of undergraduate students at the University of Malaya, some of whom declare that they speak more than one heritage language. However, Coluzzi shows that despite the reported diversity, their respective heritage languages were not the first languages of many of his respondents, and there is evidence of shift away from smaller languages taking place. Coluzzi goes on to discuss the implications of these findings in relation to maintenance of heritage languages, arguing that if they are to survive there is a need for official recognition as minority or regional languages, and for language planning initiatives. These conclusions seem to be more generally applicable to all the languages other than Malay and English within Malaysia. 
The final article is by Robert Laub and concerns Malaccan Portuguese, which originates from a variety of Portuguese brought to Malacca from South Asia over 500 years ago, and subsequently influenced by Malay and English. Laub outlines the history of settlement in Malacca and the patterns of language use over time. He compares aspects of the structure of Malaccan Portuguese with similar structures in Malay, including how tense, aspect and mood are encoded and how variation between long and short forms of pronouns is patterned. He argues that Malay has influenced the historical development of these features, and locates his conclusion within the wider context of creole language studies, where the structural role of subordinate (non-coloniser) languages has tended to be downplayed.

\section{Acknowledgements}

This thematic issue was produced as part of a Newton-Ungku Omar Advanced Fellowship grant (AF 150224). We are grateful to the authors for their contributions and to all the community members involved in each of the projects discussed here. We also wish to thank all the reviewers for their time, and their constructive feedback on the papers:

Alan Norman Baxter (University of Saint Joseph, Macau)

Seong Lin Ding (Universiti Malaya)

Lise M. Dobrin (University of Virginia)

Gary Holton (University of Hawai'i at Mānoa)

James McLellan (Universiti Brunei Darussalam)

Mário Pinharanda-Nunes (University of Macau)

Sonja Riesberg (University of Cologne)

Chris Sinha (Hunan University)

Vera da Silva Sinha (University of East Anglia)

Wen-Yi Soh (Southern University College Malaysia)

Sumittra Suraratdecha (Mahidol University)

Su Hie Ting (Universiti Malaysia Sarawak)

Roselind Wan (Universiti Teknologi PETRONAS)

Xiaomei Wang (Xiamen University Malaysia)

Birgül Y1lmaz (University of Westminster) 
We would also like to thank the Editor-in-Chief of the Journal of Modern Languages for giving us the opportunity to publish and guest-edit this issue.

\section{References}

Alias Abd Ghani. (2015). The teaching of indigenous Orang Asli language in Peninsular Malaysia. Procedia - Social and Behavioral Sciences 208, 253-262.

Asmah Haji Omar (2016). Positioning languages in the Malaysian education system. In Asmah Haji Omar (Ed.), Languages in the Malaysian education system: monolingual strands in multilingual settings (pp. 1-30). London \& New York: Routledge.

Coluzzi, P. (2017). Language planning for Malay in Malaysia: A case of failure or success? International Journal of the Sociology of Language, 2017(244), 17-38.

Smith, K. J. (2003) Minority language education in Malaysia: Four ethnic communities' experiences. International Journal of Bilingual Education and Bilingualism, 6(1), 52-65.

Bell, R. T., Ibrahim, Z., Ho, K. W., \& Lim, L. (2015). Malaysian Sign Language (BIM). In J. B. Jepsen, G. de Clerck, S. Lutalo-Kiingi, W. B. McGregor (Eds.), Sign languages of the world: A comparative handbook (pp. 583-606). Berlin: De Gruyter Mouton. 